\author{
Савцова Анна Валерьевна, Кабанова Ольга Валерьевна, \\ Теличко Дарья Юрьевна, Ревегук Наталья Андреевна
}

\title{
ЭВОЛЮЦИЯ НОРМАТИВОВ ОБЯЗАТЕЛЬНЫХ РЕЗЕРВОВ ЦЕНТРАЛЬНОГО БАНКА РОССИЙСКОЙ ФЕДЕРАЦИИ
}

В статье подчеркивается важсность изучения обязательных резервов как для коммерческих банков, так и для экономики страны в целом. Рассматриваются понятие политики обязательных резервов, законодательная база, регламентирующая политику обязательных резервов в Российской Федерации, виды политики обязательного резервирования. Проводится анализ изменения нормативов обязательных резервных требований в России и выявляется причинно-следственная связь. Делается заключение о том, что от размера нормативов обязательных резервов будут зависеть такие макроэкономические показатели, какликвидность банков и предложение в стране денежной массы.

Ключевые слова: политика обязательных резервов, административная политика обязательных резервов, рыночная политика обязательных требований, резервные требования, нориатив обязательных резервных требований, коэффициент усреднения.

\section{Anna Savtsova, Olga Kabanova, Darya Telichko, Natalya Reveguk EVOLUTION OF NORMATIVE OF REQUIRED RESERVES OF THE CENTRAL BANK OF THE RUSSIAN FEDERATION}

In the article emphasize the importance of the study of mandatory reserves, both for commercial banks and for the economy of the country as a whole. The article deals with the concept of the policy of mandatory reserves, the legislative framework governing the policy of mandatory reserves in the Russian Federation, the types of policy of mandatory reservation. The analysis of changes in the norms of mandatory reserve requirements in Russia is carried out and the cause-and-effect relationship is revealed. It is concluded that the size of the required reserves will depend on macroeconomic indicators such as the liquidity of the banking sector and the supply of money in the country.

Key words: policy of required reserves, administrative policy of required reserves, market policy of mandatory requirements, reserve requirements, standard of mandatory reserve requirements, averabing coefficient.

Bведение / Introduction. Обязательные резервы, выступая ликвидными средствами, являются своеобразным гарантом обязательств коммерческих банков по депозитам их клиентов. Но также резервные требования оказывают непосредственное влияние на снижение прибыли банков, поскольку средства, хранящиеся на счете в Банке России, не приносят никакого дохода, а если бы эти средства находились в обороте, то эффект был бы обратным. Несмотря на имеющиеся минусы, резервные требования являются важным инструментом для поддержания ликвидности кредитных учреждений, так как в случае если большое количество вкладчиков единовременно захотят снять свои денежные средства, а у кредитной организации данных средств не будет в наличии, то спасательным кругом будут являться их резервные счета в Банке России. Следовательно, анализ обязательных резервов как одного из инструментов денежно-кредитной политики является в нынешних условиях особенно актуальным.

Maтериаль и методы / Materials and methods. В процессе изучения нормативов обязательных резервных требований использовались статистические, логические методы, а также методы обобщения и сравнения. 
Peзультаты / Results. В Российской Федерации политика обязательных резервов стала применяться с 1991 года, в то время как в зарубежных странах ее использование началось в начале XX века.

В нашей стране уровень нормативов рассматриваемых обязательных резервов регламентируется законодателем с помощью двух основных нормативных актов: Федерального закона от 10.07.2002 № 86-Ф3 «О Центральном Банке Российской Федерации (Банке России)» и Положения Банка России от 01 декабря 2015 года № 507-П «Об обязательных резервах кредитных организаций» $[1,2]$.

В соответствии со статьей 35 Федерального закона «О Центральном Банке Российской Федерации (Банке России)», установленные обязательные требования к резервам представляются одним из основных инструментов денежно-кредитной политики Банка России.

На сегодняшний день главными задачами политики обязательных резервов являются:

a) обеспечение постоянного уровня ликвидности коммерческих банков;

б) регулирование денежной массы, то есть ЦБ РФ посредством увеличения нормы обязательных резервов, уменьшает кредитный потенциал банков и соответственно денежную массу в обращении, напротив, сокращая эту норму, ЦБ РФ высвобождает дополнительные ресурсы банков, что способствует росту активных операций банков и соответственно увеличению обращающейся денежной массы.

Резервные требования, в соответствии с законом, - это объем обязательных резервов в процентах к резервируемым обязательствам банка.

Управление обязательными резервами может быть административным, а может быть стихийным (рыночный характер). Это зависит от того, каким является сам норматив - неизменным для всех банков, видов обязательств и вкладчиков или же дифференцированным.

Административное управление имеет место быть тогда, когда используется единый норматив резервирования для всех банков и операций. По мнению специалистов, в этом случае норматив выступает как налог. По своему экономическому содержанию обязательные резервы - это бездоходные вложения, банк не может их использовать, исключением являются форс-мажкорные обстоятельства или банкротство банка.

Отчисления в обязательный резерв становится дифференцированными из-за какого-либо критерия (рис. 1), в этом случае рассматриваемый инструмент можно находить рыночным, поскольку с помощью варьирования значением норматива в отношении различных видов обязательств Банк России будет оказывать воздействие на ресурсную базу банка. Таким образом, банк сможет управлять уровнем обязательных резервов, депонированных в Банке России, посредством трансформирования структуры обязательств [3].

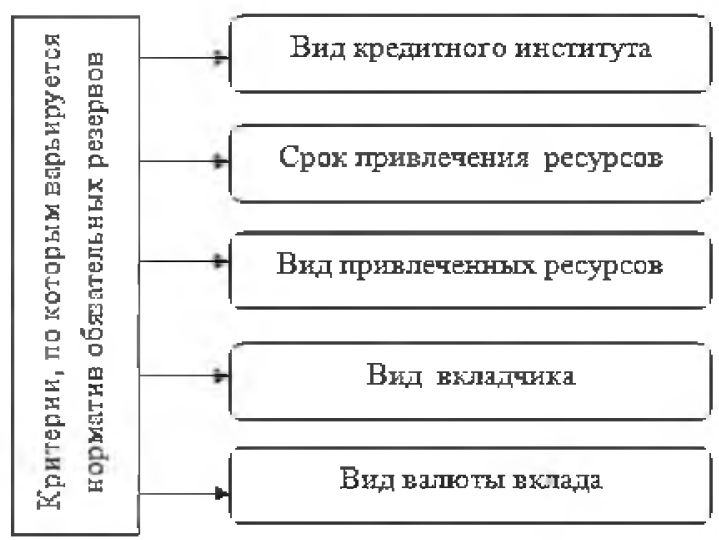

Рис. 1. Критерии, по которым осуществляется варьирование величины норматива обязательных резервов 
В Российской Федерации в период с 1 июня 1991 года по 31 января 1992 года политика обязательных резервов носила административный характер, так как устанавливался единый норматив для всех привлеченных средств в размере $2 \%$.

С 1 февраля 1992 года обязательные резервы стали активно применяющимся инструментом денежно-кредитного регулирования. С этого момента политика обязательных резервов начала применять дифференцированные подходы к определению размеров резервов, т.е. она стала рыночной (рис. 2). Данная дифференциация зависела от срока привлечения депозитов банками.

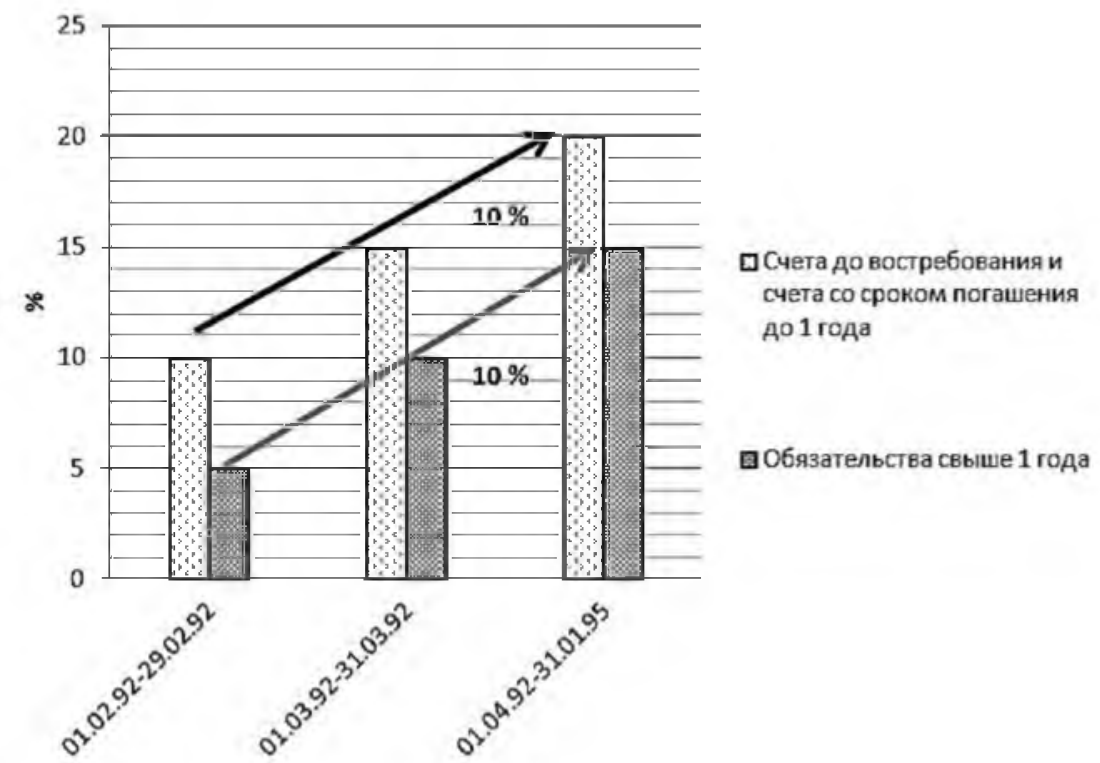

Рис. 2. Размер обязательньх резервных требований в период 01.02.1992-31.01.1995 годов

Рис. 2 отчетливо показывает, что за период с 01.02.1992 по 31.01.1995 гг. размер обязательных резервов по счетам, открытым до востребования, и со сроком погашения до одного года и обязательствам свыше одного года вырос на 10 \%, это связано с тем, что в данный период главной макроэкономической целью было снижение инфляции. Для этого Центральный банк увеличивал норму обязательных резервов для того, чтобы связать денежную массу и инфляцию.

Стоит отметить, что по счетам, открытым до востребования, и со сроком погашения до одного года норматив отчислений значительно выше, чем по обязательствам свыше года. Это обусловлено тем, что по первым наблюдается больший риск немедленного снятия вкладчиками своих денежных средств.

Несмотря на высокий норматив резервных требований в рассматриваемом периоде, коммерческими банками без каких-либо санкций нарушались требования Центрального банка из-за отсутствия жесткой дисциплины по отчислениям данных резервов. После того как в IV квартале 1994 года произошла смена руководителя Центрального банка, был полностью пересмотрен характер применения рассматриваемого инструмента российской денежно-кредитной политики.

С 1 февраля 1995 года вступили в силу такие правила как:

- применение жестких санкций, в том числе отзыв лицензии Центральным Банком по отношению к коммерческим банкам в случае неисполнения последними обязательств по отчислениям обязательных резервов;

- увеличение дифференциации норм обязательных резервов по принципу ликвидности;

- введение норм обязательного резервирования по валютным счетам. 
Вышеназванные изменения вызвали всплеск негативных эмоций у руководителей коммерческих банков, поскольку нормативы обязательных резервов на 1 февраля 1995 года были значительно завышены (таблица 1). Банкам приходилось перечислять в Центральный банк $1 / 5$ часть вкладов в национальной валюте, и, следовательно, наблюдалась потеря значительной части прибыли коммерческих банков.

Центральный банк пошел навстречу коммерческим банкам только в мае 1995 года, когда он незначительно снизил резервные требования.

Таблица 1

Нормативы отчислений в резерв за период 1995-1998 годов [5]

\begin{tabular}{|c|c|c|c|c|c|}
\hline Период действия & $\begin{array}{c}\text { Счета } \\
\text { до востребования } \\
\text { и срочпњые } \\
\text { обязательства } \\
\text { до } 30 \text { дней } \\
\text { включительно }\end{array}$ & $\begin{array}{c}\text { Срочные } \\
\text { обязательства } \\
\text { от } 31 \text { дня } \\
\text { до } 90 \text { дней } \\
\text { включительно }\end{array}$ & $\begin{array}{c}\text { Срочные } \\
\text { обязательства } \\
\text { от } 91 \text { дня } \\
\text { и более }\end{array}$ & $\begin{array}{c}\text { Счета } \\
\text { в иностранной } \\
\text { валюоте }\end{array}$ & $\begin{array}{c}\text { Вклады и депозиты } \\
\text { физических лиц } \\
\text { в рублях независимо } \\
\text { от сроков } \\
\text { (Сберб̄анк РФ) }\end{array}$ \\
\hline $01.02 .95-30.04 .95$ & 22 & 15 & 10 & 2 & \\
\hline $01.05 .95-30.04 .96$ & 20 & 14 & 10 & 1,5 & \\
\hline $01.05 .96-10.06 .96$ & 18 & 14 & 10 & 1,25 & \\
\hline $11.06 .96-31.07 .96$ & 20 & 16 & 12 & 2,5 & \\
\hline $01.08 .96-30.10 .96$ & 18 & 14 & 10 & 2,5 & \\
\hline $01.11 .96-30.04 .97$ & 16 & 13 & 10 & 5 & $10^{1}$ \\
\hline $01.05 .97-11.11 .97$ & 14 & 11 & 8 & 6 & 9,5 \\
\hline $12.11 .97-30.11 .98$ & 14 & 11 & 8 & 9 & 9,5 \\
\hline $01.12 .97-31.01 .98$ & 14 & 11 & 8 & 9 & 8 \\
\hline $01.02 .98-23.08 .98$ & \multicolumn{4}{|c|}{11} & 8 \\
\hline $24.08 .98-31.08 .98$ & \multicolumn{4}{|c|}{10} & 7 \\
\hline
\end{tabular}

Последуюшее снижение произошло ровно через год - 1 мая 1996 года, однако оно было недолгим, уже 11 июня этого года Центральный банк вновь поднял нормативы резервных требований по всем категориям. Причиной тому являлся принятый Государственной Думой федеральный закон № 62-Ф3 от 05.06.1996 года «О перечислении прибыли Центрального банка Российской Федерации в федеральный бюджет». Согласно этому закону, у ЦБ РФ изъяли 5 трлн руб., что предполагало последующее увеличение эмиссии денежных знаков на эту же сумму, однако эта мера могла бы стать причиной разрушения финансовой стабильности и провала всей экономики страны. Вследствие этого ЦБ РФ принял решение переложить на банки ответственность финансирования расходов федерального бюджета с помощью повышения нормативов, в результате чего ЦБ РФ получил множество протестов со стороны коммерческих банков. И уже 1 августа 1996 года Банк России начал постепенное снижение обязательных резервных требований по всем категориям, кроме счетов в иностранной валюте, по которым, напротив, наблюдалось увеличение резервных требований [6].

Стоит отметить, что с 1 декабря 1996 года все вклады, а также депозиты граждан в рублях, несмотря на сроки Сбербанка РФ, выделены в отдельную категорию для отчислений на резервный счет в ЦБ РФ, что свидетельствует о монополистическом положении Сбербанка РФ среди остальных коммерческих банков. Норматив резервных требований по данной категории на 1 декабря 1996 года составлял $10 \%$, а уже 24 августа 1998 года - $7 \%$. 
Для остальных коммерческих банков Банк России с 1 февраля 1998 года отменил дифференцированный подход и установил единый норматив в размере 11 \% для всех привлеченных средств, а 24 августа того же года, он его снизил на $1 \%$.

В последующие периоды нормативы обязательных резервов то уменьшались, то увеличивались, менялись категории, по которым они устанавливались, и к середине 2004 года данные нормативы стабилизировались (рис. 3).

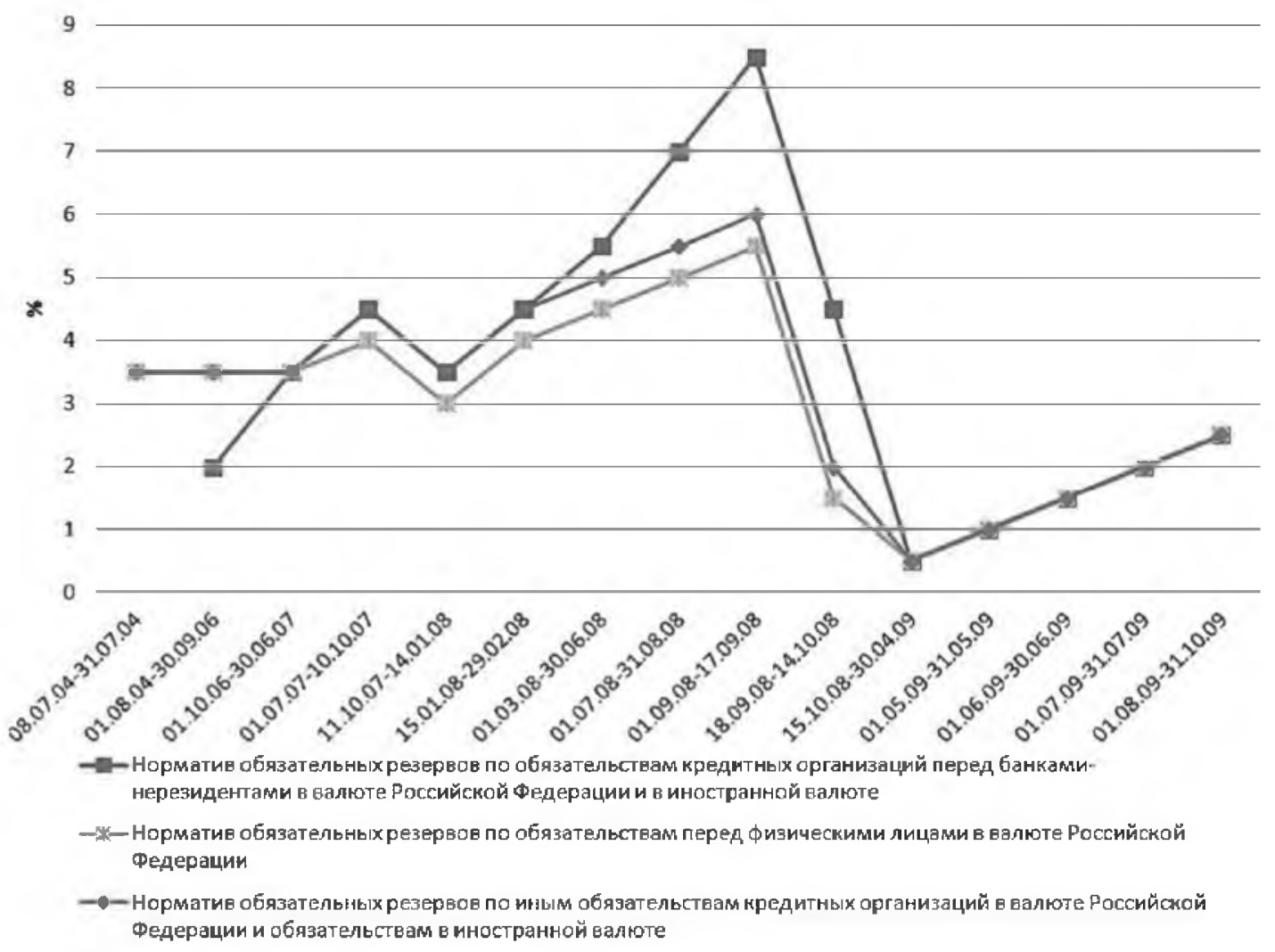

Рис. 3. Размер нормативов обязательньх резервов для трех категорий за период с 08.07.2004 по 31.10.2009 годов [5]

Как видно из рис. 3, с июля 2004 года произошло устранение дифференцированного подхода к банкам: был установлен единый уровень норматива резервных ограничений - 3,5 \% по обязательствам гражданам в рублях и прочим обязательствам, как в рублях, так и в иностранной валюте. Однако далее через месяц внедрена еще одна позиция, требующая резервных отчислений - обязательства кредитных институтов перед банками-нерезидентами в национальной и иностранной валютах. Также с августа 2004 года начал применяться коэффициент усреднения в размере 0,2 для всех кредитных организаций. Применение данного коэффициента предполагает необходимость поддержания установленного уровня остатков денежных средств на корреспондентских счетах банка на средней хронологической основе.

Из рис. 3 также видно, что с июля 2004 года по июль 2007 года, наблюдалась определенная стабильность: нормативы обязательных резервов поддерживались на приемлемом уровне, что позволило увеличить банковскую ликвидность и существенно понизить ставки по краткосрочным кредитам. Но с июля 2007 года размеры нормативов резервных требований снова начали колебаться. 
В период с сентября по 14 октября 2008 года были максимально высокие нормативы резервов: по обязательствам перед банками-нерезидентами в рублях и иностранной валюте норматив был установлен $8,5 \%$, по обязательствам перед гражданами в рублях $-5,5 \%$, по прочим обязательства и в валюте РФ, и в иностранной $-6 \%$. Причиной данного повышения является попытка снижения темпов инфляции Банком России. Также именно этот период характеризуется нарастанием темпов мирового финансового кризиса. Вследствие этого Банком России принимается решение о снижении нормативов обязательного резервирования с целью поддержания национальных банков. Минимальные значения нормативов обязательных резервов приходятся на период с 15 октября по 30 апреля 2009 года, по всем обязательствам норматив составил 0,5 \%. Но с мая 2009 года норматив обязательных резервов снова начинает свой рост, и к августу этого же года он увеличился в пятикратном размере, составив 2,5\% по всем обязательствам.

С ноября 2009 года расширилась база установления размера отчислений в резервы (таблица 2), он рассчитывался от объема обязательств в отечественной и иностранной валютах перед юридическими лицами-нерезидентами, обязательств перед физическими лицами, иных обязательств.

Таблица 2

Состав резервируемых обязательств и нормативы обязательных резервов с 01.11.2009 года по 31.12.2016 года [4]

\begin{tabular}{|c|c|c|c|c|c|c|}
\hline \multirow{2}{*}{ Период действия } & \multicolumn{2}{|c|}{$\begin{array}{c}\text { Норматив по обязательствам } \\
\text { перед юридччскими } \\
\text { лищами-нерезидентами }\end{array}$} & \multicolumn{2}{|c|}{$\begin{array}{l}\text { Норматив по обязательствам } \\
\text { перед физическими лицами }\end{array}$} & \multicolumn{2}{|c|}{$\begin{array}{c}\text { Норматив } \\
\text { по иным об̆яательствам }\end{array}$} \\
\hline & $\begin{array}{c}\text { в валюте РФ, } \\
\%\end{array}$ & $\begin{array}{c}\text { в иностранной, } \\
\%\end{array}$ & $\begin{array}{c}\text { в валюте РФ, } \\
\%\end{array}$ & $\begin{array}{c}\text { в иностранной, } \\
\%\end{array}$ & $\begin{array}{c}\text { в валюте РФ, } \\
\text { \% }\end{array}$ & $\begin{array}{c}\text { в иностранной, } \\
\%\end{array}$ \\
\hline $01.11 .09-31.01 .11$ & \multicolumn{6}{|c|}{2,5} \\
\hline $01.02 .11-28.02 .11$ & \multicolumn{2}{|c|}{3,5} & \multicolumn{2}{|c|}{3} & \multicolumn{2}{|c|}{3} \\
\hline $01.03 .11-31.03 .11$ & \multicolumn{2}{|c|}{4,5} & \multicolumn{2}{|c|}{3,5} & \multicolumn{2}{|c|}{3,5} \\
\hline $01.04 .11-28.02 .13$ & \multicolumn{2}{|c|}{5,5} & \multicolumn{2}{|c|}{4} & \multicolumn{2}{|c|}{4} \\
\hline $01.03 .13-31.03 .16$ & \multicolumn{2}{|c|}{4,25} & \multicolumn{2}{|c|}{4,25} & \multicolumn{2}{|c|}{4,25} \\
\hline $01.04 .16-30.06 .16$ & 4,25 & 5,25 & 4,25 & 4,25 & 4,25 & 5,25 \\
\hline $01.07 .16-31.07 .16$ & 4,25 & 6,25 & 4,25 & 5,25 & 4,25 & 6,25 \\
\hline $01.08 .16-31.12 .16$ & 5,00 & 7,00 & 5,00 & 6,00 & 5,00 & 7,00 \\
\hline $\begin{array}{c}\text { Темп прироста } \\
01.08 .16 / 01.11 .09, \%\end{array}$ & 100,0 & 180,0 & 100,0 & 140,0 & 100,0 & 180,0 \\
\hline
\end{tabular}

Необходимо отметить, что норматив составлял $2,5 \%$ более двух лет по всем названным обязательствам, но с февраля 2011 года началось постепенное увеличение данного норматива. С этого момента он стал дифференцированным. Далее, в августе 2016 года нормативы резервов были установлены на уровне: по обязательствам перед юридическими лицами-нерезидентами в рублях $-5 \%$, в иностранной валюте $-7 \%$; по обязательствам перед гражданами в российской валюте $-5 \%$, в иностранной валюте $-6 \%$; по прочим обязательствам в рублях $-5 \%$, в иностранной валюте $-7 \%$.

Анализ динамики позволяет сделать вывод, что темп роста размера отчислений в резерв за исследуемый период составил 100 \% по обязательствам в валюте российской Федерации и более $140 \%$ по обязательствам в иностранной валюте. Увеличение нормативов было связано с необходимостью финансирования возникшего дефицита государственного бюджета из средств резервного фонда. Повышение было необходимо для того, чтобы дестимулировать рост обязательств в иностранной валюте в структуре пассивов кредитных организаций [6]. 
С января 2017 года, как и в предыдущий период, отчисления в резерв по обязательствам в национальной валюте составили $5 \%$, по обязательствам в иностранной валюте $-7 \%$. Одним изменением является введение нормативов по долгосрочным обязательствам. Их величина аналогична вышеуказанным (рис. 4).

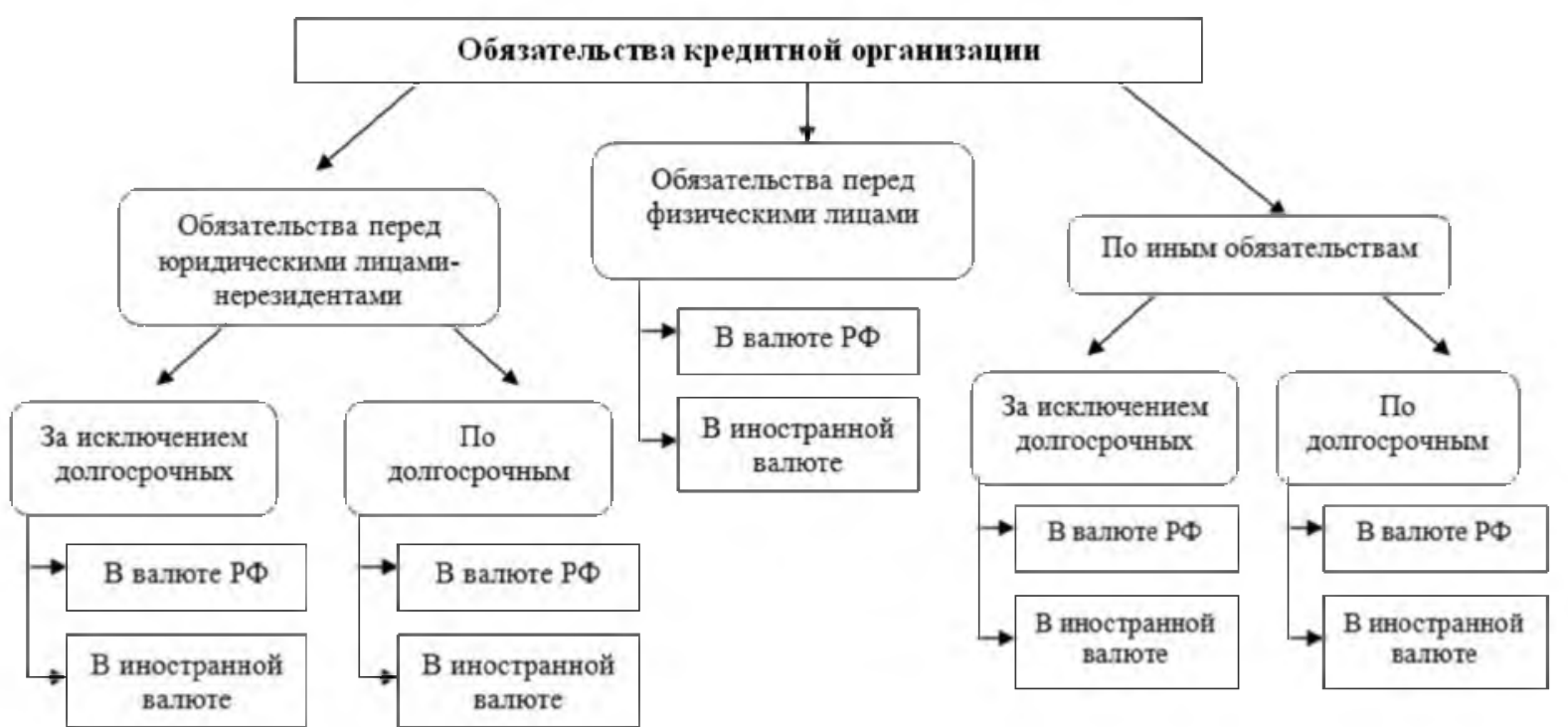

Рис. 4. Группировка обязательств кредитной организации для определения норматива обязательньх резервных требований с 2017 года по настоящее время

Следующее изменение нормативов обязательных резервов произошло в декабре 2017 года в связи с тем, что в мае этого года Президент России подписал федеральный закон от 01.05.2017 года № 92-Ф3 «О внесении изменений в отдельные законодательные акты Российской Федерации», который предусматривал введение пропорционального банковского регулирования, в связи с чем произошло разделение кредитных организаций на банки с универсальной и базовой лицензией в зависимости от размера собственных средств (капитала). Следовательно, нормативы также стали устанавливаться в зависимости от типа кредитной организации. Для банков с универсальной лицензией сохранились предыдущие значения нормативов, а для банков с базовой лицензией изменились нормативы в направлении понижения по обязательствам перед гражданами и по прочим обязательствам в рублях - $1 \%$ против $5 \%$ для банков с универсальной лицензией.

Отметим, что последнее изменение нормативов обязательных резервов совершилось 1 августа 2018 года. В настоящий момент нормативы обязательных резервов по валютным обязательствам перед физическими лицами как для банков с универсальной лицензией, так и для банков с базовой лицензией составляют $7 \%$ (ранее $-6 \%$ ), а по валютным обязательствам перед юридическими лицами-нерезидентами и иным обязательствам $-8 \%$ (ранее $-7 \%$ ). Данная мера была направлена на сокращение повышения валютных обязательств в пассивах коммерческих банков [5].

Заключение / Conclusion. Таким образом, проанализировав эволюцию изменений нормативов резервных требований в России можно сделать вывод, что в случае нахождения страны в кризисе ликвидности Центральный банк РФ осуществляет снижение нормы обязательного резервирования, а в случае высокой инфляции осуществляет ее повышение. Однако сочетание этих двух макроэкономических проблем ставит Банк России перед выбором, поскольку единственный инструмент способен разрешить одну проблему, при этом негативно влияя на другую. 


\section{ЛИТЕРАТУРА И ИНТЕРНЕТ РЕСУРСЫ}

1. О Центральном банке Российской Федерации (Банке России): Федер. закон от 10.07 .2002 г. № 86 [Электронный ресурс] // Справочно-правовая система «КонсультантПлюс». URL: http:// base. consultant.ru.

2. Об обязательных резервах кредитных организаций: положение Банка России от 01.12.2015 г. № 507 [Электронный ресурс] // Справочно-правовая система «КонсультантПлюс». URL: http:// base. consultant.ru.

3. Розанова Н. М. Денежно-кредитная политика: учебник и практикум для академического бакалавриата и магистратуры. М.: Юрайт, 2016. 410 с.

4. Информационно-правовая система «КонсультантПлюс» [Электронный ресурc]. URL: http://www. consultant.ru.

5. Официальный сайт Центрального банка Российской Федерации [Электронный ресурc]. URL: http:// www.cbr.ru/

6. Официальный сайт газеты «Коммерсантъ» [Электронный pecypc]. URL: https://www.kommersant.ru/ doc/233889

\section{REFERENCES AND INTERNET RESOURSES}

1. Central'nom banke Rossijskoj Federacii (Banke Rossii). (About Central Bank of the Russian Federation (Bank of Russia)): feder. zakon ot 10.07.2002 g. No 86. [Jelektronnyj resurs], Spravochno-pravovaja sistema «Konsul'tantPljus». URL:http:// base.consultant.ru

2. Ob objazatel'nyh rezervah kreditnyh organizacij. (About mandatory reserves of credit institutions): polozhenie Banka Rossii ot 01.12.2015 g. No 507 [Jelektronnyj resurs] // Spravochno-pravovaja sistema «Konsul'tantPljus». URL: http:// base.consultant.ru.

3. Rozanova N. M., Denezhno-kreditnaja politika (Monetary policy). M.: Jurajt, 2016. $410 \mathrm{~s}$.

4. Informacionno-pravovaja sistema Konsul'tantPljus [Jelektronnyj resurs]. URL: http://www.consultant.ru.

5. Oficial'nyj sajt Central'nogo banka Rossijskoj Federacii [Jelektronnyj resurs]. URL: http://www.cbr.ru/

6. Oficial'nyj sajt gazety Kommersant\# [Jelektronnyj resurs]. URL: https://www.kommersant.ru/doc/233889

\section{СВЕДЕНИЯ ОБ АВТОРАХ}

Савцова Аниа Валерьевна, доктор экономических наук, профессор кафедры финансов и кредита Института экономики и управления, СКФУ. E-mail: levandanna@yandex.ru

Кабанова Ольга Валерьевна, кандидат экономических наук, доцент кафедры финансов и кредита Института экономики и управления, СКФУ. E-mail: olgakabst $@$ mail.ru

Теличко Дарья Юрьевна, студент бакалавриата кафедры финансов и кредита Института экономики и управления СКФУ. E-mail: dashenka.telichko@mail,ru

Реведук Наталья Андреевна, студент бакалавриата кафедры финансов и кредита Института экономики и управления СКФУ. E-mail: reveguk.natasha@yandex.ru

\section{INFORMATION ABOUT AUTHORS}

Anna Savtsova, Doctor of Economics Sciences, Professor, Department of Finance and Credit of the Institute of Economics and management North Caucasus Federal University. E-mail: levandanna@yandex.ru

Olga Kabanova, Candidate of Economics Sciences, associate Professor, Department of Finance and Credit of the Institute of Economics and management North Caucasus Federal University. E-mail: olgakabst $a$ mail.ru

Darya Telichko, graduate student, Department of Finance and Credit of the Institute of Economics and management North Caucasus Federal University. E-mail: dashenka.telichko@mail,nu

Natalya Reveguk, graduate student, Department of Finance and Credit of the Institute of Economics and management North Caucasus Federal University. E-mail: reveguk.natasha@yandex.ru 